\title{
Is Asperger's syndrome a useful diagnosis?
}

\author{
A D Cox
}

The first published account of early infantile autism was in 1943 and Asperger's original paper appeared the following year. ${ }^{1}$ Childhood autism and Asperger's syndrome are in many ways similar and there is continuing argument as to whether it is useful or appropriate to consider them as separate entities. ${ }^{2} 3$

In the 9th revision of the International Classification of Diseases (ICD-9) infantile autism is a subcategory of psychoses with origin specific to childhood and Asperger's syndrome is not a listed subcategory (see table 1). ${ }^{4}$ The revised American classification in the Diagnostic and Statistical Manual of Mental Disorders (DSMIII), considered that infantile autism was no longer appropriately classified with psychoses and included it as a subcategory under the general classification of pervasive developmental disorders. ${ }^{5-7}$ Again there is no separate subcategory for Asperger's syndrome. Pervasive developmental disorders are seen as characterised by a qualitative impairment in the development of reciprocal social interaction and of verbal and non-verbal communication skills, autistic disorder being the one acknowledged specific subcategory. Field trials have shown that there are two mandatory criteria for autistic disorder: an appreciable lack of awareness of the existence or feelings of others, and persistent preoccupations with parts of objects. ${ }^{8}$ Gillberg has criticised the use of the term pervasive developmental disorder preferring 'autism spectrum disorders' and he has recently suggested that a separate diagnostic designation of infantile autism doesn't seem to make a 'lot of sense any more'.9 Although he argues that the term 'pervasive developmental disorder' is too loosely defined and that the disorders included in the category are 'specific' and/or 'partial' rather than pervasive, it seems likely that there is no intended difference in the range of disorders covered by the term 'pervasive developmental disorder' and 'autism spectrum disorder'.

Despite Gillberg's criticisms and sceptism about subclassification, the 10th revision of the

United Medical and Dental Schools of Guy's and St Thomas's Hospitals, London

Correspondence to: Professor A D Cox, Bloomfield Clinic, Department of Child and Adolescent Psychiatry, Guy's Hospital, Guy's Hospital,

London SE1 9RT.
299 Psychoses with origin specific to childhood:

1.0 Infantile autism

1.1 Disintegrative psychosis

1.9 Unspecified is adopting the term, pervasive developmental disorders, and includes subcategories not only of childhood autism but also Asperger's syndrome (see table 2). ${ }^{10}$ How is it proposed that this diagnostic term is to be used? It is useful? It appears that Gillberg uses Asperger's syndrome as the equivalent of 'high functioning autism'. If that is really how the term is to be used, then one may indeed wonder whether it is appropriate to have a separate subcategory. In his original description, Asperger emphasised a number of features. ${ }^{11}$ Firstly, the child usually begins to speak at the age expected in normal children and a full command of grammar is sooner or later acquired. However, the manner of speaking is often pedantic and subjects engage in monologues rather than conversations. Use of gestures tends to be restricted and comprehension of others' facial expressions and gestures is poor. Secondly, there is an impairment of two way social interaction with a lack of ability to understand and use the rules governing social behaviour. It appears that there is not a primary desire to withdraw from social contact, rather a lack of ability to comprehend social situations and respond appropriately. Thirdly, as in infantile autism, there is commonly in early childhood a preoccupation with particular activities and resistance to change. Later there are all absorbing circumscribed interests and engagement in routines. Fourthly, gross motor movements are characteristically clumsy and uncoordinated.

It will be seen that the description of Asperger's syndrome is substantially similar to the picture in some relatively intelligent individuals with a diagnosis of infantile autism. Indeed, Asperger originally believed that people with his syndrome were of high intelligence. What stands out as different from infantile autism is the superficially normal early language development. The term, Asperger's syndrome, therefore proposes that there are a group of

Table 2 International Classification of Diseases, 10th revision

\begin{tabular}{ll}
\hline F84 & Pervasive developmental disorders: \\
F84.0 & Childhood autism \\
F84.1 & Atypical autism \\
& F84 10 Atypicality in age of onset \\
& F84 $\cdot 11$ Atypicality in symptomatology \\
& F84 $\cdot 12$ Atypicality in both age of onset and \\
F84.2 & Rett's syndrome \\
F84.3 & Other childhood disintegrative disorder \\
F84.5 & Asperger's syndrome
\end{tabular}


individuals who have a disorder of social development similar to that found in infantile autism, but with a pattern of early language development that appears grossly normal; at least as regards the milestones that are usually recorded. Tantam states that there is no difficulty with propositional language but 'marked pragmatic impairment' ${ }^{3}$ The core features of autistic social development are often referred to as 'Wing's triad': deficits in social interaction, communication, and imagination. ${ }^{12}$

A major diagnostic difficulty in infantile autism is that the classical criteria are most easily recognised among children aged between 3 and 5 years. It is at this stage of development that aloofness and indifference in social interactions may be most readily observed alongside a lack of language, including a lack of comprehension of speech and repetitive physical activities. The pattern of symptomatology changes, however, and changes most noticeably among more able individuals.

Wing has described what she calls an 'autistic continuum' (table 3 ) in which the most severely disabled individuals are aloof and indifferent in social interaction, the more able or least handicapped characterised by bizarre one sided social approaches. ${ }^{13}$ More able autistic individuals who develop language move from no language at age 3 to quite extensive use of speech which, as in Asperger's syndrome, is used in a grammatical but one sided and literal fashion. The suggestion is that there are parallels in function in the areas of social interaction, communication, and obsessional interests and activities. Those of low ability, or those of higher ability at an earlier stage of development show aloofness, no language, and simple repetitive activities. More able individuals, particularly at a later stage of development, display a more elaborate picture of social ineptness, circumscribed interests, and concrete egocentric use of language. This analysis could be seen to reinforce the notion that Asperger's syndrome is no more than high functioning autism. There are individuals, however, with autistic social development who have appreciably abnormal early language development including a significant delay in comprehension of speech, who subsequently attain to a high functioning picture. There are others, also high functioning, who do not have a history of abnormal early language development, at least in a gross sense. ${ }^{14}$

Does this matter? If it is true that a similar high functioning autistic picture can be obtained on the basis of quite different early language development, what are the implications for our understanding of the relationship between social and language development? It may be that there are subtle or not so subtle differences among the high functioning 'autistic' individuals with these discrepancies in early language development. For example, it has been suggested that those with superficially normal early language development speak spontaneously more often and demonstrate an active, if restricted fantasy life ( $S$ Wolff, personal communication).

It is just this difference in early language development that is used as a basis for the establishment of the subcategory of Asperger's syndrome in ICD-10. It states that in Asperger's syndrome there is 'A lack of any clinically significant general delay in language or cognitive development'. ${ }^{10}$ The criteria for qualitative impairments in reciprocal social interaction are identical with those for childhood autism. The same is true for the restricted, repetitive and stereotyped patterns of behaviour, interest, and activities. However, it is commented that it would be 'less usual for these to include either motor-mannerisms or preoccupation with part objects or non-functional elements of play materials'. The aim appears to be to draw attention to the existence of children with social developmental disorders of a type found in childhood autism but without a major disorder of language development affecting comprehension and expression.

There may be an empirical descriptive basis for a diagnosis of Asperger's syndrome, but there does not appear yet to be any definite psychopathological nor neuropathological distinction from high functioning childhood autism. A recent study of the use of intonation to communicate, however, which compared subjects with Asperger's syndrome with high functioning autistics concludes that 'an early history of deviant language' 'is associated with more pronounced failure to use intonation to communicate effectively later during childhood and adolescence' (A J Fine et al, unpublished observations). There were also differences in the ability to decode non-verbal social information. ${ }^{15}$

Considerable progress has been made in trying to understand the nature of the psychological processes which are dysfunctional in childhood autism. Two main views are, on the one hand that there is a deficit in the innate ability to interact emotionally with others, and on the other an impairment in the cognitive process of metarepresentation. ${ }^{16} 17$

The ability to form representations of representations is considered necessary in order to 'mentalise' - that is, to think and reason about one's own and others' minds. Attribution of beliefs and intentions to others is said to reflect an individual's 'theory of mind'. Communica-

Table 3 The autistic continuum (features most often used in diagnosis) $)^{13}$

\begin{tabular}{|c|c|c|c|}
\hline Item & $\begin{array}{l}\text { Tend to be seen } \\
\text { in the most severely } \\
\text { handicapped/retarded }\end{array}$ & & $\begin{array}{l}\text { Tend to be seen in } \\
\text { least severely } \\
\text { handicapped/retarded }\end{array}$ \\
\hline $\begin{array}{l}\text { Social interaction } \\
\text { Social communication } \\
\text { (verbal and non-verbal) }\end{array}$ & $\begin{array}{l}\text { (1) Aloof and indifferent (2) Approaches for } \\
\text { physical needs only } \\
\begin{array}{ll}\text { (1) No communication } & \text { (2) Needs only }\end{array}\end{array}$ & $\begin{array}{l}\text { (3) Passively accepts } \\
\text { approaches } \\
\text { (3) Replies if approached }\end{array}$ & $\begin{array}{l}\text { (4) Makes bizarre one } \\
\text { sided approaches } \\
\text { (4) Spontaneous, but } \\
\text { repetitive, one sided, } \\
\text { odd }\end{array}$ \\
\hline
\end{tabular}


tion that is not modified by inferences about other's beliefs and intentions is literal and one sided. ${ }^{18}$

The metarepresentational deficit theory has been criticised on the ground that deficiencies in joint attention behaviour are a feature of autistic children and that these normally emerge between 6 and 9 months of age, at least six months before the capacity for metarepresentation. ${ }^{19}$

Further criticism comes from the other main theory that argues that the exclusively cognitive formulation of the metarepresentational hypothesis misunderstands the connection between social and emotional development. ${ }^{2021}$ Hobson suggests that autistic individuals fail to develop an adequate concept of persons because 'an impairment in biologically based capacities for engaging in (and representing) personal relatedness, especially affective relatedness'. This impairment is present before the stage at which joint attention usually develops.

This second main view has in turn been attacked on the ground that there is no empirical support for the hypothesised affective disorder in infancy. ${ }^{22}$ In addition, recent work suggests autistic children can develop selective attachments and that they also pick up the feelings of others. ${ }^{1823}$ Sigman and Mundy regard the children's difficulties as one of social comprehension-the identification of the significance and meaning of their experiencesrather than one of social responsiveness. ${ }^{23}$

The various theories are concerned with a social psychological deficit that is conceived as a core dysfunction in both autism and Asperger's syndrome. If the underlying dysfunction is detectable before language develops then the level of deficit could be comparable in the two conditions when individuals are matched for intelligence quotient and language level. If the core dysfunction lies in metarepresentation, however, it could be expected to be alleviated in those whose language development is relatively preserved. In other words it would be predicted that those with Asperger's syndrome would have better empathy than those with autism. Whether this is so is not known.

Although there is increasing evidence of neuropathology among autistic children, ${ }^{9}$ and a wide variety of specific pathologies may underlie the manifestation of the syndrome, there is still considerable debate about localisation. Neuropsychological studies do not assist in this respect. ${ }^{17}$ Recent investigation by electroencephalography has supported the notion that there may be deficits in information processing ( $\mathrm{H}$ van Engeland, paper given at European Medical Research Councils workshop; Brussels, November 1989), ${ }^{24}$ but it has been proposed that the most consistent recent findings point to brain stem pathology. ${ }^{9}$

From the genetic point of view there is disagreement about the significance of the fragile $\mathrm{X}$ anomaly, although a very recent authoritative review states that it is 'now clear that the proportion of autistic individuals with fragile $X$ is no higher and may even be lower than the proportion of mentally retarded individuals with fragile $X^{\prime} \cdot{ }^{25}$ It is further suggested that among individuals with fragile $\mathrm{X}$ social anxiety is more characteristic than social indifference and that hyperactivity and attentional problems are extremely common with frequent abnormalities in spoken language. It is nevertheless considered that this genetic anomaly may be important in a small number of individuals with autism. Other evidence supports the overall significance of genetic factors in autism, although there is still some doubt as to the extent to which any of them is specific for the social developmental disorder as opposed to certain cognitive abnormalities. ${ }^{25}{ }^{26}$ It is not evident what the position is with regard to Asperger's syndrome and this is partly because it is unclear whether research into high level autistic children can be considered research into Asperger's syndrome. DeLong and Dwyer found that high functioning autistics have a positive family history for Asperger's syndrome and low functioning autistics have a high incidence of abnormal neurological findings. ${ }^{27}$ Bipolar affective illness was also more common among families of high function autistics. This study claims that there was little distinction between high functioning autism and Asperger's syndrome among its probands, but the criteria used for the diagnosis of Asperger's syndrome did not include superficially normal early language development.

With regard to the prevalence of Asperger's syndrome, it has recently been reported to be of the order of $2 \cdot 6-3$ per 1000 children with a heavy male preponderance as in childhood autism. ${ }^{28}$ However, the Gillbergs used delayed language development and mild or moderate impairment of language comprehension as inclusion criteria for Asperger's syndrome alongside 'superficially perfect expressive language'. These criteria obscure the difference between Asperger's syndrome and high functioning autism. The problem appears to arise from a desire not to assign a diagnosis of autism to individuals with 'superficially perfect expressive language' in adolescence who met criteria for autism at age 3 to 5 years. Nevertheless it must be recognised that there are considerable difficulties in drawing the line between normality and pathology for empathic aspects of social development.

\section{Conclusion and comment}

In clinical practice it can often appear a somewhat sterile academic exercise to decide which subcategory of pervasive development disorder is appropriate for a given child. The phrase 'autistic spectrum' is problematic because the abnormalities of development in the different areas do not correlate very exactly. For example, knowledge of a child's general intellectual level does not predict whether they have an autistic social developmental abnormality, although it is of course more common among those with low intelligence. Wing and Gould reported that half of the severely mentally retarded have the 'triad' of impairments in social recognition, social communication, and social understanding. ${ }^{29}$ Similarly, a developmental language disorder affecting comprehension does not necessarily predict a major social 
developmental disorder, although recent follow up has suggested that such children do have some social difficulty, if not of severity that would make a diagnosis of pervasive developmental disorder appropriate. ${ }^{30}$

Although there is a danger that children are assigned to a diagnostic slot because they do not fit, or that disagreement between experts leads to unnecessary confusion for the parents, Asperger's syndrome is, on balance, a useful diagnosis.

There is a clear advantage in selecting specific subgroups such as those with childhood autism or Asperger's syndrome as defined in ICD-10 for research purposes, because it may help disentangle the relationship between different aspects of development. Clinically the diagnosis of Asperger's syndrome is valuable in that it draws attention to the fact that in young children there may be significant abnormalities of social development of autistic type even where other aspects appear relatively normal. In addition the specific diagnostic label can be of use to some parents in helping them come to terms with the nature of their children's disabilities. It can be helpful also in obtaining appropriate resources. Because the different developmental problems do not run in parallel, however, this does not preclude the need to address the specific problems of individual children. ${ }^{13}$ 1 Wing L. Asperger's syndrome: a clinical account. Psychol

2 Szatmari P, Bartolucci G, Bremner R. Asperger's syndrome and autism: comparison of family history and outcome. Dev Med Child Neurol 1989;31:709.

3 Tantam D. Asperger's syndrome. F Child Psychol Psychiatry 1988;29:245-55.

4 Rutter M, Shaffer D, Sturge C. A guide to a multiaxial classification scheme for psychiatric disorders in childhood and adolescence. London: Institute of Psychiatry, 1975.

5 American Psychiatric Association. Diagnostic and statistical manual of mental disorders: DSM-III. 3rd Ed. Washington DC: American Psychiatric Association, 1980.

6 American Psychiatric Association. Diagnostic and statistical manual of mental disorders: DMS-III revised. 3rd Ed, revised. Washington DC: American Psychiatric Association, 1987.

7 Rutter M, Schopler E. Autism and pervasive developmental disorders: concepts of diagnostic issues. $f$ Autism Dev Disord 1987;17:159-86.

8 Siegel B, Vukicevic J, Elliott GR, Kraemer HC. The use of sigmal detection theory to assess DSM-III R criteria for autistic disorder. I Am Acad Child Adolesc Psychiatry 1989;28:542-8.

9 Gillberg C. Autism and pervasive developmental disorders. f Child Psychol Psychiatry 1990;31:99-119.

10 World Health Organisation. Mental and behavioural disorders (including disorders of psychological development), orders (including disorders of psychological development), diagnostic criteria for research. International classi
diseases. 10th Revision. Geneva: WHO, 1990.

11 Van Krevelen DA. Early infantile autism and autistic psychopathy. Fournal of Autism and Childhood Schizophrenia 1971;1:82-6.

$12 \mathrm{Wing}$ L. Autism: possible clues to the underlying pathology-I: clinical facts. In: Wing L, ed. Aspects of autism:biological research. London: The National Autistic Society/Gaskell/Royal College of Psychiatrists, 1988:1-10.

13 Wing L. The autistic continuum. In: Wing L, ed. Aspects of autism:biological research. London: The National Autistic Society/Gaskell/Royal College of Psychiatrists, 1988:v-viii.

14 Bishop DVM. Autism, Asperger's syndrome and semanticpragmatic disorder: where are the boundaries? $\mathrm{Br} \mathcal{F}$ Disord Commun 1989;24;107-21.

15 Szatmari P, Bremner R, Nagy J. Asperger's syndrome: a review of clinical features. Can $\mathcal{F}$ Psychiatry 1989;34: 554-60.

16 Baron-Cohen S. Social and pragmatic deficit in autism:cognitive or affective? I Autism Dev Disord 1988;18:379-402.

17 Frith U. Autism:possible clues to the underlying pathologyIII: psychological facts 1988 . In: Wing L, ed. Aspects of autism:biological research. London: The National Autistic autism:biological research. London: The National Autistic

18 Frith U. A new look at language and communication in Frith U. A new look at language and commun

19 Mundy P, Sigman M. The theoretical implications of jointattention deficits in autism. Development and Psychopathology $1989 ; 1: 173-83$.

20 Hobson P. Concerning knowledge of mental states. $\mathrm{Br} \mathcal{F}$ Med Psychol 1990;63:199-214.

21 Hobson RP. On sharing experiences, Development and Psychopathology 1989;1:197-203.

22 Leslie AM, Happe F. Acute autism and ostensive communication: the relevance of metarepresentation. Development and Psychopathology 1989;1:205-12.

23 Sigman M, Mundy P. Social attachments in autistic children. f Am Acad Child Adolesc Psychiatry 1989;28:74-81.

24 Courchesne E, Lincoln AJ, Yeung-Courchesne R, Elmasian $\mathbf{R}$, Grillon C. Pathophysiological findings in non-retarded autism and receptive developmental language disorder. f Autism Dev Disord 1989;1:1-17.

25 Rutter M, McDonald H, Le Couteur A, Harrington $\mathbf{R}$ Bolton P, Bailey A. Genetic factors in child psychiatric
, Bolton P, Bailey A. Genetic factors in child psychiatric
disorders-II empirical findings. $\mathcal{f}$ Child Psychol Psychiatry disorders-II empi

26 Folstein SE, Rutter ML. Autism:familial aggregation and genetic implications. F Autism Dev Disord 1988;18:3-30.

27 DeLong GR, Dwyer JT. Correlation of family history with specific autistic groups: Asperger's syndrome and bipolar affective disease. F Autism Dev Disord 1988;18:593-600.

28 Gillberg C, Gillberg IC. Asperger's syndrome: some epidemiological considerations: a research note. $\mathcal{F}$ Child Psychol Psychiatry 1989;30:631-8.

29 Wing L, Gould G. Severe impairments of social interaction and associated abnormalities in children: epidemiology and classifications. F Autism Dev Disord 1979;9:11-30.

30 Cantwell DP, Baker L, Rutter M, Mawhood L. Infantile aut ism and developmental receptive dysphasia: a comparative follow-up into middle childhood. $\mathcal{f}$ Autism Dev Disord 1989;19:19-31. 